\title{
DEVELOPMENT OF THE NEXT GENERATION OF METEOROID AND ORBITAL DEBRIS SHIELDS
}

\author{
S.J. Ryan ${ }^{1}$, E.L. Christiansen ${ }^{2}$, D.M. Lear ${ }^{2}$ \\ ${ }^{1}$ USRA Lunar and Planetary Institute, 3600 Bay Area Blvd., Houston TX 77058 \\ ${ }^{2}$ NASA Johnson Space Center, Houston, TX 77058
}

\begin{abstract}
The novel structure of metallic foams is of interest in the design of next-generation debris shields as it introduces physical mechanisms that are advantageous to hypervelocity impact shielding (e.g. increased fragmentation/melt/vaporization, energy dissipation, etc.). Preliminary investigations have shown improved shielding capability over traditional spacecraft primary structures. In this paper, the results of a current hypervelocity impact test program on metallic open-cell foam core sandwich panels are reported. A preliminary ballistic limit equation has been derived from the experimental results, and is presented in a form suitable for implementation in risk assessment software codes.
\end{abstract}

Keywords: Hypervelocity, orbital debris, ballistic limit equation, cellular materials.

PACS: 62.50.-p, 62.20.Fe, 47.40.Nm

\section{INTRODUCTION}

In 1947 Fred Whipple proposed a "meteor bumper" in order to protect spacecraft from impact of high speed meteoroids [1]. A thin metallic bumper, Whipple argued, placed at a distance in front of the vehicle pressure hull, would dissipate the penetrating power of meteoroids. From Apollo through to the International Space Station (ISS), this concept has provided the underlying design motivation in almost all micrometeoroid and orbital debris (MMOD) shields. With sufficiently high impact velocities, and when effectively sized (relative to the impacting projectile), a thin bumper plate acts to induce compressive shocks in both the projectile and bumper structures which, upon release from free surfaces, are capable of inducing fragmentation, melting, and vaporization in both impacting bodies. As the fragmented debris cloud progresses down-range following perforation of the bumper plate, radial velocities imparted during the shocking process lead to lateral expansion, resulting in the impact of a dispersed cloud of material upon the shield rear wall (pressure hull).

With a steadily increasing orbital debris population density, the capability of protective shields on manned spacecraft must increase in order to maintain currently acceptable penetration and failure risks. Towards this goal, recent MMOD shielding designs have incorporated intermediate fabric layers [2], multiple bumper plates [3], and laminated composite plates [4], to achieve significant increases in capability while maintaining Whipple's underlying concept. However, a substantial percentage of the dedicated mass of these shields (up to $35 \%$ [5]) can be consumed as non-ballistic mass required for installation (stiffeners, fasteners, etc.).

Recent studies at NASA Johnson Space Center's Hypervelocity Impact Technology Facility (HITF) have investigated primary structure-suitable panels that possess intrinsic MMOD shielding capabilities. In applying dualpurpose configurations, the non-ballistic structural mass can be substantially reduced. 


\section{SHIELDING PERFORMANCE OF STRUCTURAL PANELS}

Due to their high stiffness, high strength and low weight, honeycomb (HC) sandwich panels are ideally suited for application as spacecraft primary structures. However, their performance under impact of micrometeoroid and orbital debris (MMOD) particles is poor due to the HC cell walls, which act to restrict the expansion of debris following perforation of the sandwich panel front facesheet. Nonetheless, HC sandwich panel primary structures are common for most unmanned satellites, as well as some manned vehicles, due to cost and/or mission restraints that prevent the inclusion of an additional protective structure.

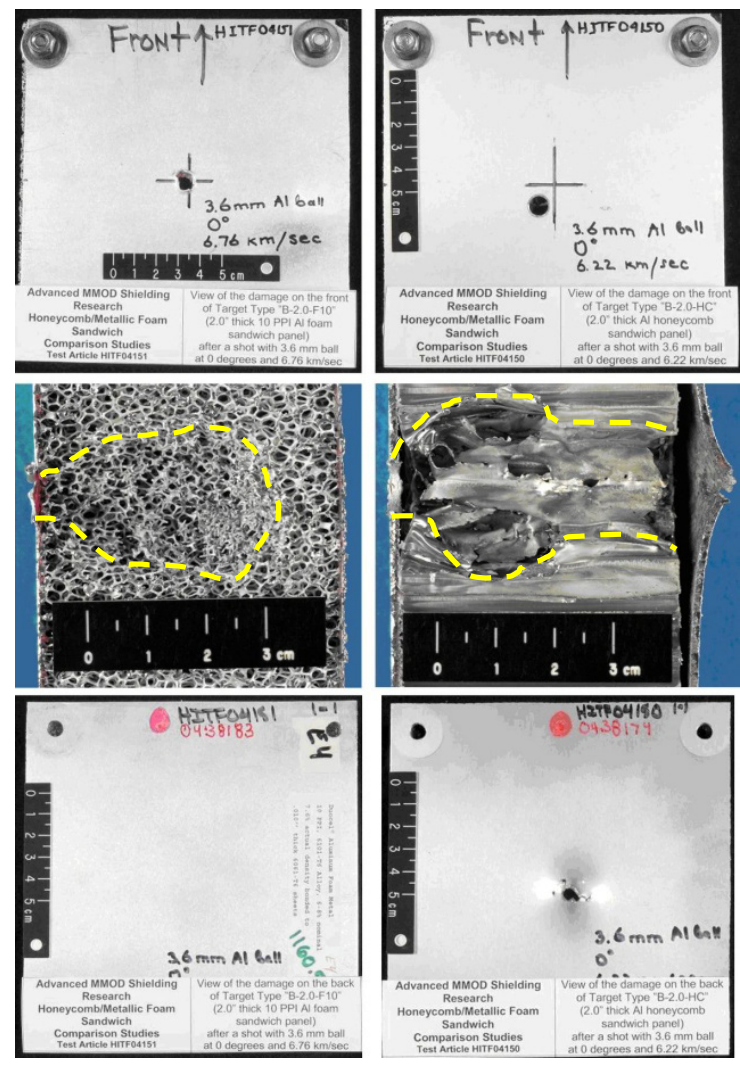

Figure 1. Comparison of damages in an open cell foam core (left) and honeycomb core (right) sandwich panel structures impacted at nominally identical conditions (3.6 mm diameter A12017-T4 sphere at $6.49 \pm 0.27 \mathrm{~km} / \mathrm{s}$ and $0^{\circ}$ ). Front top to bottom: front, core, rear facesheet. Projectile traveling from left to right.
Metallic foams are a relatively new class of materials with low density and novel physical, mechanical, thermal, electrical and acoustic properties. They offer significant performance gains in light, stiff structures, for the efficient absorption of energy, thermal management, etc [6]. There are two competing types of metallic foams: open cell and closed cell. Although closed cell foams are capable of retaining some residual atmosphere, which may aid in deceleration of penetrating fragments via drag, open cell foams are considered the more promising technology. Open cell foams are generally of lower weight, and provide a higher degree of homogeneity than lowdensity closed-cell metallic foams.

Preliminary investigations of the performance of open-cell foam core sandwich panel structures have identified potential improvements over traditional honeycomb core panels. In Figure 1 a comparison between damage to $5.08 \mathrm{~cm}$ thick sandwich panel structures of comparable areal density induced by impact of $3.6 \mathrm{~mm}$ diameter Al2017-T4 spheres at $\sim 6.5 \mathrm{~km} / \mathrm{s}$ with normal incidence is shown. Although the foam is shown to limit fragment cloud radial expansion to an equal or greater degree than the honeycomb, the foam core is clearly superior under this particular impact condition.

\section{HYPERVELOCITY IMPACT (HVI) ON OPEN-CELL FOAM SANDWICH PANELS}

The multi-shock shield [3] consists of multiple aluminum/Nextel fabric bumpers that induce multiple shocks within an impacting projectile. Each non-isentropic shock and isentropic release event acts to raise the material internal energy (or temperature), decreasing fragmentation strength and leading to melt and sublimation at lower impact velocities than required for a single bumper configuration. For correctly sized configurations, this concept can result in mass savings of $30 \%$ over comparable single-bumper configurations. For impact on open-cell metallic foams, secondary impacts between projectile and bumper fragments on individual foam ligaments is expected to reproduce the multi-shock concept, leading to fragmentation, melting, and vaporization at lower impact velocities. Tests on a foam bumper configuration for ESA's Columbus module [5] 
found evidence of incipient melting at velocities as low as $2.6 \mathrm{~km} / \mathrm{s}$, with complete melt reported at 4 $\mathrm{km} / \mathrm{s}$. In comparison, for impact on a metallic Whipple shield complete melt is calculated to occur upon release for 1-D impacts between 7-8 $\mathrm{km} / \mathrm{s}$ [7] and above $8 \mathrm{~km} / \mathrm{s}$ in $2 \mathrm{D}$ hydrocode calculations [8].

Under loading, the microstructure of metallic foams collapses plastically at a near-constant stress (plateau stress), providing them with a long, flat stress-strain curve and the ability to absorb large amounts of energy by plastic deformation. As a result, foam structures have commonly been considered as good protective materials to mitigate shocks and blast loads. However, improperly designed foam structures under more intensive external loads (e.g. blast) have been found to actually increase transmitted pressure loading if the densification regime is rapidly reached [9]. For MMOD impact, the relevant load case is a radially expanding solid/liquid/gas cloud at hypervelocity. Under these conditions plastic deformation and compaction of foam ligaments at the leading edge of the expanding debris cloud is expected to provide a degree of energy absorption as the response is localized. In Figure 2 a foam core sandwich panel is shown following impact of a 2.7 $\mathrm{mm}$ diameter Al2017-T4 sphere at $6.99 \mathrm{~km} / \mathrm{s}$ with oblique $\left(45^{\circ}\right)$ incidence. The image colors have been inverted to highlight the compacted region of foam at the leading edge of the damage cone.

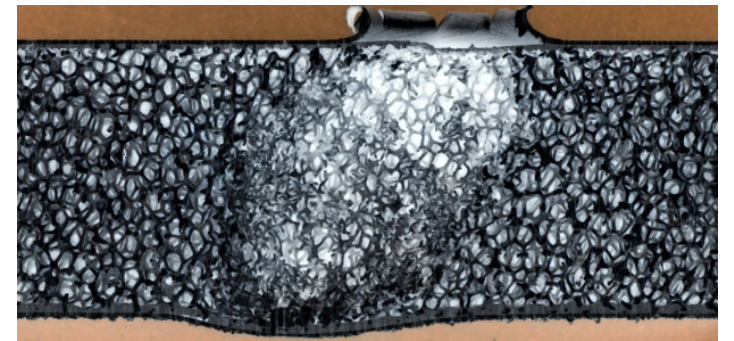

Figure 2. Foam core sandwich panel damage following impact of an aluminum sphere at hypervelocity.

\section{IMPACT TEST RESULTS AND ANALYSIS}

To investigate their hypervelocity impact performance, 17 impact tests were performed on sandwich panels with $25.40 \mathrm{~mm}$ thick aluminum foam cores bonded to $0.254 \mathrm{~mm}$ thick Al6061-T6 facesheets. The foam cores have a nominal density of $6-8 \%$ that of the base Al6101-T6 material, a pore density of 40 PPI (Pores Per linear Inch), and are manufactured by ERG Aerospace (Oakland) under the trade name Duocel. The areal density of the panel was measured as $0.7677 \mathrm{~g} / \mathrm{cm}^{2}$. An overview of test conditions and results (pass/fail) are given in Table 1. All testing was performed at NASA JSC's White Sands Test Facility 0.17-cal two-stage light gas gun [10].

Table 1. Summary of impact testing.

\begin{tabular}{ccccc}
\hline Test No. & $\begin{array}{c}\text { Projectile } \\
\text { diameter } \\
(\mathrm{cm})\end{array}$ & $\begin{array}{c}\text { Angle } \\
(\mathrm{deg})\end{array}$ & $\begin{array}{c}\text { Velocity } \\
(\mathrm{km} / \mathrm{s})\end{array}$ & Result \\
\hline 8263 & 0.20 & 0 & 6.52 & Fail \\
8270 & 0.25 & 45 & 6.78 & Pass \\
8271 & 0.27 & 45 & 6.99 & Pass \\
8267 & 0.32 & 60 & 6.57 & Pass \\
9007 & 0.34 & 60 & 6.91 & Pass \\
8279 & 0.34 & 0 & 2.62 & Fail \\
8585 & 0.25 & 45 & 2.44 & Fail \\
8421 & 0.22 & 45 & 2.68 & Pass \\
8422 & 0.25 & 0 & 2.75 & Fail \\
8424 & 0.23 & 0 & 4.68 & Fail \\
8427 & 0.26 & 45 & 4.78 & Pass \\
8248 & 0.28 & 45 & 4.76 & Pass \\
8423 & 0.21 & 0 & 2.34 & Fail \\
8567 & 0.19 & 0 & 2.2 & Pass \\
8568 & 0.20 & 0 & 6.63 & Pass \\
8569 & 0.27 & 45 & 6.66 & Fail \\
8420 & 0.20 & 0 & 4.43 & Pass \\
\hline
\end{tabular}

Ballistic limit equations (BLEs) define the limits of structural perforation in terms of projectile diameter and impact velocity. Using the experimental data listed in Table 1 to empiricallyanchor the equations, a BLE has been derived for use with open-cell foam core aluminum sandwich panels. The BLE is divided into three regimes, defined by the projectile state at impact upon the rear facesheet (based on empirical evidence):

For an intact projectile $(V \leq 2 / \cos \theta)$ :

$$
d_{c}(v)=\left[\frac{5.106 \cdot t_{S P}\left(\rho_{S P} / \rho_{p}\right)^{0.5}}{C_{1} \cdot v^{2 / 3}(\cos \theta)^{\alpha}}\right]^{18 / 19}
$$


where $t_{S P}$ is the sandwich panel total thickness in $\mathrm{cm}, \rho_{p}$ is the projectile density in $\mathrm{g} / \mathrm{cm}^{3}$, and $\rho_{\mathrm{SP}}$ is the sandwich panel density in $\mathrm{g} / \mathrm{cm}^{3}\left(\rho_{\mathrm{SP}}=A D_{S P} / t_{S P}\right)$.

For a fully fragmented projectile $(V \geq 5.5 / \cos \theta)$ :

$$
d_{c}(v)=\frac{t_{f s}^{2 / 3} \cdot t_{\text {foam }}^{1 / 3} \cdot\left(\sigma_{y} / 70\right)^{1 / 3}}{0.866 \cdot C_{2} \cdot \rho_{f s}{ }^{1 / 9} \rho_{p}^{1 / 2} v^{2 / 3}(\cos \theta)^{\beta}}
$$

where $t_{f s}$ is the facesheet thickness in $\mathrm{cm}, t_{\text {foam }}$ is the core thickness in $\mathrm{cm}, \sigma_{y}$ is the facesheet yield strength in ksi, $\rho_{f s}$ is the facesheet density in $\mathrm{g} / \mathrm{cm}^{3}$.

For a partially-fragmented projectile in the intermediate velocity regime, i.e. $\mathrm{V}_{\mathrm{LV}} / \cos \theta<\mathrm{V}<$ $\mathrm{V}_{\mathrm{HV}} / \cos \theta$, linear interpolation is used.

An overview of the constants used in Eq. (1)-(2) are summarized in Table 2.

Table 2. Summary of ballistic limit equation constants.

\begin{tabular}{cl}
\hline Constant & Value \\
\hline$C_{1}$ & $C_{1}=-1.09 \cdot t_{S P}{ }^{2}+6.72 \cdot t_{S P}+5.5$ \\
$C_{2}$ & $C_{2}=0.15 \cdot t_{\text {foam }}{ }^{-0.6}$ \\
$\alpha$ & 0.80 \\
$\beta$ & 0.85 \\
\hline
\end{tabular}

The ballistic limit curve is shown in Figure 3 for the foam SP structure along with test results. At $45^{\circ}$ the equation is slightly conservative in the intermediate regime, however the majority of equation predictions are good.

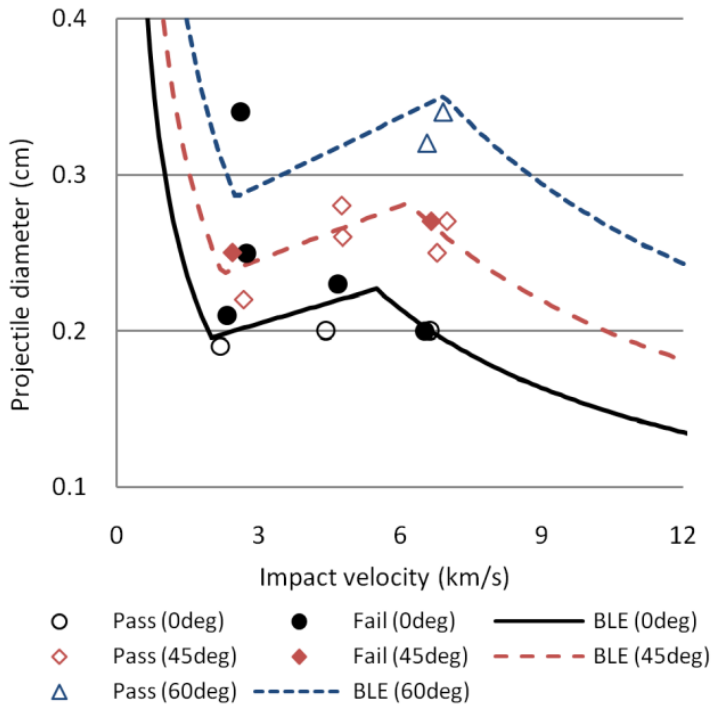

Figure 3. Ballistic limit curve of the sandwich panel.

\section{CONCLUSIONS}

Preliminary impact tests on metallic foam core sandwich panel structures have identified substantial shielding performance improvements over traditional spacecraft primary structures (e.g. honeycomb sandwich panels). Such shields are of interest as they lessen the non-ballistic shielding mass required for current configurations (e.g. stuffed Whipple shield). A series of 17 hypervelocity impact tests were performed on open-cell foam core sandwich panel structures at normal and oblique incidence, from which a preliminary ballistic limit equation has been derived. The equation constants incorporate specific structural and material properties which should enable its extension to other configurations. The equation is presented in a form suitable for use in MMOD risk analysis software.

\section{REFERENCES}

1. Whipple, F.L., "Meteorites and Space Travel", The Astronomical Journal 1161, pp. 131, 1947.

2. Christiansen, E.L., Crews, J.L., Williamsen, J.E., Robinson, J.H., Nolen, A.M., "Enhanced Meteoroid and Orbital Debris Shielding", International Journal of Impact Engineering 17, pp. 217-228, 1995. 
3. Cour-Palais, B.G., Crews, J.L., "A Multi-Shock Concept for Spacecraft Shielding", International J. of Impact Engineering 10, pp. 135-146, 1990.

4. Destefanis, R., Faraud, M., Trucchi, M., "Columbus Debris Shielding Experiments and Ballistic Limit Curves”, Int. J. Impact Eng 23, pp. 181-192, 1999.

5. Destefanis, R., Schaefer, F., Lambert, M., Faraud, M., Schneider, E., "Enhanced Space Debris Shields for Manned Spacecraft", International Journal of Impact Engineering 29, pp. 215-226, 2003.

6. Ashby, M.F. et al., "Metal Foams: A Design Guide", Butterworth-Heinemann, Boston, 2000.

7. Swift, H.F., "Hypervelocity Impact Mechanics", in: Impact Dynamics (Zukas ed.), Wiley \& Sons, 1982.

8. Alme, M., Rhodes, C (Jr), "A Computational Study of Projectile Melt in Impact with Typical Whipple Shields", Int. J. Impact Eng. 17, pp. 1-12, 1995.

9. Hanssen, A.G., Enstock, L., Langseth, M., "CloseRange Blast Loading of Aluminum Foam Panels", Int. J. Impact Engineering 27, pp. 593-618, 2002.

10. Anon., "NASA White Sands Test Facility: Hypervelocity Impact Testing Facility", url: http://www.nasa.gov/centers/wstf/laboratories/hyper velocity/index.html, accessed: 2009/05/26. 